\title{
INFLUÊNCIA DA POSIÇÃO DA ESTACA NO RAMO SOBRE O ENRAIZAMENTO DE Pfaffia glomerata (Spreng.) Pedersen EM DOIS SUBSTRATOS ${ }^{1}$
}

\author{
SHOOT CUTTING POSITION EFFECT ON ROOTING OF Pfaffia \\ glomerata (Spreng.) Pedersen IN TWO SUBSTRATES
}

\section{Fernando Teixeira Nicoloso ${ }^{2}$ Roni Paulo Fortunato ${ }^{3}$ Marco Aurélio de Freitas Fogaça ${ }^{4}$}

\section{RESUMO}

A fáfia (Pfaffia glomerata (Spreng.) Pedersen) é uma espécie que vem sendo utilizada na medicina popular contra várias enfermidades, tais como inflamações e reumatismo, bem como para combater fadiga e estresse. Por isso, os recursos naturais dessa espécie têm sido consideravelmente explorados e informações sobre métodos para sua propagação são necessárias. $O$ objetivo deste trabalho foi avaliar a viabilidade da propagação vegetativa via estaquia, a influência da posição da estaca no ramo e do substrato no processo de enraizamento de estacas de fáfia. Os tratamentos consistiram de uma combinação bifatorial $(4 x$ 2), representados por quatro posições das estacas no ramo (basal, mediana-basal, mediana-apical e apical) e dois substratos (areia média + casca de arroz carbonizada e solo + casca de arroz carbonizada, 1:1 v/v). As estacas, de 15 a $20 \mathrm{~cm}$ de comprimento, foram obtidas a partir de cortes sucessivos da base do ramo para o ápice. $O$ delineamento experimental foi inteiramente cazualisado com cinco repetições, sendo a parcela experimental constituída de 20 estacas. $O$ experimento foi instalado em 17 de Julho de 1997 e teve duração de 90 dias, sob condição de temperatura ambiente. Os resultados indicaram que: a estaquia é um método adequado para a propagação da fáfia, estacas obtidas das porções medianas e basal dos ramos apresentam maior capacidade de enraizamento que as apicais e a combinação de solo + casca de arroz carbonizada é um substrato viável para a estaquia e para o posterior desenvolvimento das mudas a campo.

Palavras-chave: propagação vegetativa, estaquia, Pfaffia glomerata, substrato, tipo fisiológico da estaca, produção de mudas.

\section{SUMMARY}

Pfaffia glomerata (Spreng.) Pedersen is a medicinal herb that has been used in the Brazilian folk medicine against several illnesses, such as inflammations and reumatism. It has also been playing the role of a ginseng-like tonic herb, helping to fight fatigue and combat stress. Therefore, wild resources have been exploited considerably and informations about suitable methods for its propagation are needed. The aim of this work was to evaluate the suitability of vegetative propagation via cuttings, the shoot cutting position effect, and the substrate on rooting process of Pfaffia cuttings. The treatments followed a $4 \times 2$ factorial scheme, involving four positions of cuttings in the shoot (basal, middle-basal, middle-apical, and apical) and two substrates (sand + carbonized rice husk and soil + carbonized rice husk, $1: 1 \mathrm{v} / \mathrm{v})$. The cuttings, ranged from 15 to $20 \mathrm{~cm}$ length, were obtained by sucessive cuts of the shoot from the base to the tip. The experimental design was completely randomized with five replications, and 20 cuttings per experimental unity. The experiment was installed on July $17^{\text {th }}, 1997$ and last for 90 days under ambient temperature. The results allowed to indicate that vegetative propagation via cuttings is a feasible method, cuttings taken from the shoot basis and the shoot middle positions show the best physiological features to rooting, and the combination of soil + carbonized rice husk is a suitable substrate for rooting and for the growth of the plantlet in the field.

Key Words: vegetative propagation, cuttings, Pfaffia glomerata, substrate, physiological types of cuttings.

\section{INTRODUÇÃO}

A busca da cura das enfermidades humanas através do uso de fitofármacos é uma prática bastante antiga. A partir da evolução da indústria química, principalmente, após as guerras mundiais, aumentou o uso de medicamentos sintéticos. Porém, atualmente, em função do elevado custo destes pro-

\footnotetext{
${ }^{1}$ Projeto financiado pela FAPERGS.

${ }^{2}$ Engenheiro Agrônomo, PhD., Professor Adjunto, Departamento de Biologia, Centro de Ciência Naturais e Exatas, Universidade Federal de Santa Maria (UFSM), 97105-900, Santa Maria, RS. E-mail: nicoloso@sm.conex.com.br. Autor para correpondência.

${ }^{3}$ Acadêmico do curso de Agronomia, UFSM, Bolsista da FAPERGS.

${ }^{4}$ Engenheiro Agrônomo, Mestrando em Agronomia, UFSM, Bolsista da CAPES. 
dutos e, também, da impossibilidade de obtenção da síntese química de substâncias com estruturas complexas, tem-se procurado novamente a obtenção de novos produtos alternativos. Atualmente, tem-se observado em nível mundial um grande interesse na produção de fitoterápicos.

Uma planta que tem chamado a atenção na medicina popular é a Pfaffia glomerata (Spreng.) Pedersen, espécie pertencente à família Amaranthaceae, conhecida popularmente como fáfia e corango-sempre-viva. A fáfia é uma erva alta lianosa, característica do planalto catarinense, onde apresenta possivelmente dispersão irregular e descontínua. É uma planta seletiva higrófita e heliófita bastante rara, ocorre principalmente à beira de rios e nas orlas das matas de galerias, onde pode receber bastante luz (SMITH \& DOWNS, 1972). É utilizada como anti-reumático, antinflamatório e analgésico, efeitos atribuídos a substâncias como o ácido oleanólico, ecdisterona, nortriterpenóides, triterpenóides e ecdysteróides que, segundo SHIOBARA et al. (1993), encontram-se presentes em tecidos da planta.

A exemplo do que acontece com inúmeras espécies de interesse medicinal e agronômico, a propagação vegetativa via estaquia pode constituirse num método eficiente para multiplicação da fáfia. Vários fatores estão envolvidos no processo de enraizamento de estacas, tanto fatores exógenos como endógenos. Para FACHINELLO et al. (1994), a condição fisiológica da estaca possui grande importância no processo, pois ao longo do ramo o conteúdo de carboidratos e de substâncias promotoras e inibidoras do crescimento nos tecidos apresentam variação, sendo que estacas obtidas de diferentes porções do ramo tendem a diferir quanto ao potencial de enraizamento. VLACHOV (1988), analisando a capacidade de enraizamento de três tipos de estacas de Platanus acerifolia Ait., obtidas ao longo da extensão do mesmo ramo (basais, medianas e apicais), verificou que as estacas basais apresentaram potencial significativamente superior.

O substrato usado na propagação via estaquia assume papel relevante no processo de enraizamento, devendo procurar atender às necessidades do processo de iniciação das raízes adventícias e seu posterior crescimento (KOMISSAROV, 1969). Segundo HARTMANN \& KESTER (1990), o substrato ideal deve possuir, quanto a características físicas, ótimas condições de aeração, alta capacidade de retenção de água, bem como boa drenagem. Segundo FACHINELLO et al. (1994), a areia fina, sob condições de nebulização, pode compactar-se, induzindo à formação de raízes menos ramificadas; já o solo tem como desvantagem a fácil disseminação de doenças e, também, a pouca drenagem quando usado em sistema de nebulização. DUTRA \& KERSTEN (1996) verificaram que a areia + serragem, dentre nove outros substratos, proporcionaram o maior percentual de enraizamento em estacas de ameixeira (Prunus saliciana Lindl.) coletadas em janeiro e março, atribuindo a essa combinação as melhores condições físicas do substrato, através do equilíbrio entre os teores de água e ar e adequada densidade.

O presente trabalho objetivou avaliar a viabilidade da propagação vegetativa via estaquia, o efeito da posição da estaca no ramo e do substrato no enraizamento de estacas de Pfaffia glomerata (Spreng.) Pedersen.

\section{MATERIAL E MÉTODOS}

O presente trabalho foi conduzido no viveiro do Departamento de Ciências Florestais do Curso de Engenharia Florestal da Universidade Federal de Santa Maria (UFSM), RS. Os tratamentos consistiram de uma combinação bifatorial (4 x 2), representados por quatro posições das estacas no ramo (basal, mediana-basal, mediana-apical e apical) e dois substratos: (i) casca de arroz carbonizada + areia média lavada e (ii) casca de arroz carbonizada + solo (horizonte A de solo Podzólico vermelho amarelo, sem adubação) na proporção de 1:1 (v/v). As estacas, de 15 a $20 \mathrm{~cm}$ de comprimento, foram obtidas a partir de cortes sucessivos da base do ramo para o ápice, de ramos que possuíam entre 80 e $140 \mathrm{~cm}$ de comprimento. As folhas presentes nos ramos, em pequeno número, foram retiradas, visando à uniformização das estacas. O delineamento experimental foi inteiramente cazualisado com cinco repetições, sendo a parcela experimental constituída de 20 estacas. As estacas foram condicionadas de modo que a gema superior ficasse dois centímetros acima da superfície do substrato. Utilizaram-se recipientes com dois litros de capacidade para o substrato, colocando-se duas estacas por vaso.

A coleta das estacas foi realizada de plantas cultivadas no Jardim Botânico da UFSM, no dia 17 de Julho de 1997. Nesse mesmo dia, fez-se a instalação do experimento. Após 90 dias em condições de temperatura ambiente, foram avaliadas as seguintes variáveis: comprimento total do sistema radicular por estaca (segundo o método descrito por TENNANT, 1975), massa seca de raízes, massa seca da parte aérea (desconsiderando a da estaca), número de folhas por brotação e comprimento de brotações por estaca. Nos 30 dias iniciais do período experimental, coincidindo com o inverno, fez-se o controle parcial da temperatura ambiente à noite, elevação de aproximadamente $3^{\circ} \mathrm{C}$, com o uso de 
túnel plástico (altura de $80 \mathrm{~cm}$ ), visando evitar a queima dos tecidos da estaca pelo frio. Nos últimos 30 dias, as estacas ficaram sob sombrite (malha 50\% de extinção de luz) a uma altura de $40 \mathrm{~cm}$. Quando necessário, na ausência de precipitação pluviométrica, realizou-se irrigação pela adição de $150 \mathrm{ml}$ de água por vaso. Aos 60 dias, aplicou-se adubação foliar com solução completa de HOAGLAND \& ARNON (1950) diluída a 10\%.

Para verificar uma possível existência de interação entre a capacidade de enraizamento da estaca e o posterior potencial de desenvolvimento das mudas, realizou-se o plantio de aproximadamente $25 \%$ das estacas enraizadas, aos 90 dias do período experimental, em canteiros contendo solo previamente preparado com adubação química (2,0kg de NPK 5:20:20 por $\mathrm{m}^{3}$ de solo) e orgânica (15\% de matéria orgânica de origem vegetal). Aos seis meses após o transplantio das estacas enraizadas, foram avaliadas as seguintes variáveis: número de brotações, diâmetro e altura das brotações por estaca. A análise estatística dos parâmetros de crescimento foi realizada pelo teste de Duncan, em nível de $5 \%$ de probabilidade.

\section{RESULTADOS E DISCUSSÃO}

A percentagem de enraizamento, comprimento total do sistema radicular por estaca e número de folhas por brotação de estacas, oriundas das porções basal e medianas, apresentaram resposta significativamente superior às estacas da porção apical (tabela 1). Com relação à massa seca de raízes e das brotações, as estacas basais e medianasbasais apresentaram-se superiores às medianas-apicais e apicais (tabela 1). Portanto, quanto mais próximo da base do ramo em que as estacas são formadas, maiores são as condições que elas têm para a formação da muda. Além disso, esses resultados indicam uma dependência entre o número de folhas produzidas por brotação e a capacidade de enraizamento da estaca, bem como do desenvolvimento da raiz (através do comprimento e do acúmulo de massa seca), haja vista a considerável correlação entre as variáveis massa seca de brotações e massa seca de raízes $\left(r^{2}=0,82\right)$. Essa observação vai ao encontro daquelas apresentadas por HARTMANN \& KESTER (1990) e FACHINELLO et al. (1994), que consideram as folhas como um dos fatores pre- ponderantes no enraizamento, através da produção de fitormônios, tal como ácido indolácetico, e de cofatores essenciais a esse processo.

O comprimento das brotações não foi afetado significativamente pela posição da estaca no ramo (tabela 1). Desse modo, os resultados sugerem que as folhas (avaliadas principalmente pela produção de massa seca), produzidas durante o processo de enraizamento, apresentam-se como um fator chave no enraizamento. FACHINELLO \& KERSTEN (1981) constataram em pessegueiro, que o tratamento com ácido indolbutírico, uma auxina sintética, aumentou a percentagem de enraizamento das estacas com folhas, não obtendo influência nas estacas sem folhas. ALMEIDA et al. (1991) observaram que estacas de maracujazeiro com folhas cortadas pela metade tiveram menor desempenho em comparação às estacas mantidas com folhas inteiras. DUTRA \& KERSTEN (1996) verificaram que estacas de ameixeira com maior queda de folhas apresentaram menores percentuais de enraizamento e maior perdas de estacas.

O melhor enraizamento de estacas oriundas das porções basal e medianas do ramo podem estar, provavelmente, relacionados à maior concentração de carboidratos presentes nessas porções. Resultados semelhantes a estes foram obtidos por LAZZARI (1997) em Platanus acerifolia.

Tabela 1 - Efeito da posição da estaca no ramo e do substrato sobre o percentual
de enraizamento (\%ER), comprimento de raízes (compR), massa seca
de raízes (msR), comprimento das brotações (compB), número de fo-
lhas por brotação (n ${ }^{\circ}$ FB) e massa seca de brotação (msB) em estacas
de Pfaffia glomerata (Spreng.) Pedersen, aos 90 dias do início da es-
taquia. Os valores das variáveis para a posição da estaca no ramo refe-
rem-se à média dos dois substratos. UFSM, Santa Maria, 1998.

*Tratamentos com médias não ligadas por mesma letra, na vertical, diferem pelo teste de Duncan em nível de $5 \%$ de probabilidade. 
Os resultados do efeito de substratos são apresentados na tabela 1 . O tipo de substrato não influenciou o percentual de enraizamento, proporcionando valor próximo a $90 \%$. Este resultado mostra que, independente do substrato testado, a fáfia apresenta alto potencial de pegamento através da estaquia.

O substrato solo + casca de arroz carbonizada foi significativamente superior à areia + casca de arroz carbonizada nos parâmetros massa seca de raízes, número de folhas por brotação e massa seca de brotos (tabela 1). Possivelmente, este resultado esteja relacionado às melhores condições físicas da combinação solo + casca de arroz carbonizada, que apresentou maior umidade volumétrica e porosidade total (tabela 2). DUTRA \& KERSTEN (1996) verificaram que a areia + serragem, dentre nove outros substratos, proporcionaram o maior percentual de enraizamento em estacas de ameixeira (Prunus saliciana Lindl.) coletadas em janeiro e março, atribuindo a essa combinação as melhores condições físicas do substrato, através do equilíbrio entre os teores de água e ar e adequada densidade.

Apesar de ter-se observado a existência de raízes bastante ramificadas nos dois tipos de substratos, envolvendo todo o volume do vaso, verificou-se através de observações visuais da parte aérea, que ambos substratos não forneceram nutrientes em quantidades suficientes ao adequado desenvolvimento das plantas, sendo esse problema mais acentuado na combinação areia + casca de arroz carbonizada. Para minimizar a deficiência nutricional, realizou-se adubação foliar (dose única) aos 60 dias do período experimental. A deficiência nutricional constatada pela análise visual das folhas também demonstra, além da pobreza química dos substratos utilizados, que as estacas possuem um limitado suprimento de nutrientes orgânicos e inorgânicos, como reserva em seus tecidos. Isso explica talvez o menor percentual de enraizamento das estacas apicais (tabela 1) com diâmetro menor que as basais.

O efeito da posição da estaca no ramo e do substrato de enraizamento sobre o desenvolvimento das mudas de fáfia a campo, aos seis meses após o transplantio das estacas enraizadas, são apresentados na tabela 3 . Os resultados indicam que as estacas obtidas das porções medianas e basal apresentaram maior diâmetro, número e maior altura das brotações que as apicais. Quanto ao efeito do substrato, aquelas estacas enraizadas enraizamento que as apicais. A combinação de solo + casca de arroz carbonizada é um substrato viável para a estaquia e para o posterior desen- na combinação solo + casca de arroz carbonizada mostraram, a exemplo do observado no processo da estaquia (tabela 1), melhor desenvolvimento que as obtidas na estaquia em areia + casca de arroz carbonizada.

\section{CONCLUSÕES}

A estaquia é um método adequado para a propagação da fáfia (Pfaffia glomerata (Spreng.) Pedersen). Estacas obtidas das porções medianas e basal dos ramos apresentam maior capacidade de

Tabela 3 - Efeito da posição da estaca no ramo e do substrato de enraizamento sobre o desenvolvimento das mudas de Pfaffia glomerata (Spreng.) Pedersen, aos 6 meses após transplantio, em relação ao número, diâmetro e altura das brotações (média aritmética de no mínimo três observações). UFSM, Santa Maria, 1998.

Substrato areia + casca de arroz carbonizada

\begin{tabular}{cccc}
\hline $\begin{array}{c}\text { Posição da } \\
\text { estaca no ramo }\end{array}$ & $\mathrm{n}^{\circ}$ de brotações & diâmetro $(\mathrm{mm})$ & $\begin{array}{c}\text { altura das } \\
\text { brotações }(\mathrm{cm})\end{array}$ \\
\hline Apical & 1,0 & 4,1 & 26,0 \\
mediana-apical & 1,8 & 5,4 & 60,3 \\
mediana-basal & 1,6 & 5,3 & 55,0 \\
basal & 2,0 & 4,6 & 55,3 \\
\hline
\end{tabular}

Substrato solo + casca de arroz carbonizada

Posição da $\quad n^{\circ}$ de brotações diâmetro $(\mathrm{mm})$ altura das estaca no ramo brotações $(\mathrm{cm})$

\begin{tabular}{cccc}
\hline apical & 1,5 & 5,0 & 69,0 \\
mediana-apical & 2,5 & 7,0 & 71,2 \\
mediana-basal & 1,9 & 6,8 & 60,2 \\
basal & 2,1 & 6,5 & 74,1
\end{tabular}


volvimento das mudas a campo.

\section{REFERÊNCIAS BIBLIOGRÁFICAS}

ALMEIDA, L.P., BOARETO, M.A.C., SANTANA, R.G., $\boldsymbol{e}$ t al. Estaquia e comportamento de maracujazeiro (Passiflora edulio SIMS F. flavicarpa DEG) propagados por vias sexual e vegetativa. Revista Brasileira de Fruticultura, Cruz das Almas, v. 13, p. 153-156, 1991.

FACHINELLO, J.C., KERSTEN, E. Efeito do ácido indolbutírico na percentagem de estacas semi-lenhosas enraizadas de pessegueiro (Prunus persica L. Batsch) cv "Diamante", em condições de nebulização. Revista Brasileira de Fruticultura, Cruz das Almas, v. 3, p. 49-50, 1981.

FACHINELLO, J.C., HOFFMAN, A., NACHTIGAL, J.C., $\boldsymbol{e} \boldsymbol{t} \boldsymbol{a l}$. Propagação de plantas frutíferas de clima temperado. Pelotas: Editora e Gráfica UFPEL, 1994. 179 p.

HARTMANN, H.T., KESTER, D.E. Propagacion de plantas princípios y praticas. México: Compañia editorial Continental, 1990. $760 \mathrm{p}$.

HOAGLAND, D.R., ARNON, D.I. The water-culture method for growing plants without soil. California Agricultural Experimental Station, 1950. 38 p., Circular, 347.

DUTRA, L.F, KERSTEN, E. Efeito do substrato e da época de coleta dos ramos no enraizamento de estacas de ameixeira
(Prunus saliciana Lindl.). Ciência Rural, Santa Maria, v. 26, n. 3, p. 361-366, 1996.

KOMISSAROV, D.A. Biological basis for the propagation of woody plants by cuttings. Jerusalem, 1969. $250 \mathrm{p}$.

LAZZARI, M. Influência de tipos fisiológicos de estacas, épocas de coleta, zinco, boro e ácido indolbutírico no enraizamento de Platanus acerifolia Ait. Santa Maria-RS. 61p. Dissertação (Mestrado em Agronomia) - Curso de Pósgraduação em Agronomia, Universidade Federal de Santa Maria, 1997.

SHIOBARA, Y., INOUE, S., KATO, K., et al. A nortripenoids, tripenoids and ecdysteroids from Pfaffia glomerata. Phytochemistry, Oxford, v. 32, n. 6, p.1527-1530, 1993.

SMITH, L.B., DOWNS, R.J. Flora ilustrada catarinense: Amarantáceas. Itajaí, 1972. 110 p.

TENNANT, D. A test of a modified line intersect method of estimating root length. The Journal of Ecology, v. 63, n. 3, p. 995-1001, 1975.

VLACHOV, D.D. Vegetative propagation of sp. Platanus L . through rooting of cuttings. Acta Horticulture, Wageningen, v. 226 , p. $375-378,1988$.

Ciência Rural, v. 29, n. 2, 1999. 